\title{
PERFORMANCE ANALYSIS ON DYNAMIC WIRELESS CHARGING FOR ELECTRIC VEHICLE USING FERRITE CORE
}

\author{
Siti Hajar YusofF*, Amira Aziera Abdullah, Nadia Nazieha Nanda \\ AND AHMED SAMIR ABED BADAWI
}

Department of Electrical and Computer Engineering, Faculty of Engineering, International Islamic University Malaysia, Jalan Gombak, 53100 Kuala Lumpur, Malaysia

*Corresponding author: sitiyusoff@iium.edu.my

(Received: $18^{\text {th }}$ October 2020; Accepted: $15^{\text {th }}$ July 2021; Published on-line: $4^{\text {th }}$ January 2022)

\begin{abstract}
The technology of dynamic Wireless Power Transfer (WPT) has been accepted in the Electric Vehicle (EV) industry. Recently, for a stationary EV charging system, the existence of a ferrite core improves power efficiency. However, for dynamic wireless charging, the output power fluctuates when the EV moves. Two main obstacles that must be dealt with is air-gaps and misalignment between the coils. This paper investigates clear design guidelines for fabrication of an efficient Resonant Inductive Power Transfer (RIPT) system for the EV battery charging application using a ferrite core. Two different geometry shapes of ferrite core, $\mathrm{U}$ and I cores, will be investigated and tested using simulation and experimental work. The proposed design was simulated in JMAG 14.0, and the prototype was tested in the laboratory. The expected output analysis from these two techniques was that the power efficiency of the ferrite pair should first be calculated. From the analysis and experimental results, it is seen that the pair of ferrite cores that used a $\mathrm{U}$ shape at the primary and secondary side provides the most efficient coupling in larger air-gap RIPT application with $94.69 \%$ on simulation JMAG 14.0 and $89.7 \%$ from conducting an experiment.
\end{abstract}

ABSTRAK: Teknologi Alih Kuasa Wayarles (WPT) dinamik telah diterima pakai dalam Kenderaan Elektrik (EV). Baru-baru ini, kewujudan teras ferit dalam sistem pengecasan pegun EV dapat meningkatkan kecekapan kuasa. Namun, kuasa pengecasan ini akan berubah apabila EV bergerak bagi sistem pengecasan wayarles secara dinamik. Dua halangan utama yang harus ditangani adalah ketidakjajaran dan jarak antara dua gegelung. Kajian ini merupakan garis panduan yang jelas mengenai rekaan fabrikasi dan kecekapan sistem Alih Kuasa Induktif Resonan (RIPT) bagi aplikasi pengecasan bateri EV menggunakan teras ferit. Dua bentuk geometri teras ferit, iaitu teras U dan I telah dikaji dan diuji menggunakan simulasi dan eksperimen. Rekaan ini telah disimulasi menggunakan JMAG 14.0 dan prototaip diuji di dalam makmal. Kedua-dua teknik ini diharapkan dapat menghasilkan kecekapan kuasa yang sama. Dapatan kajian menunjukkan kedua-dua teras ferit pada sisi primer dan sekunder berbentuk $U$ mempunyai gandingan paling efisien bagi jarak paling besar antara 2 gegelung menggunakan aplikasi RIPT dengan $94.69 \%$ simulasi JMAG 14.0 dan $89.7 \%$ secara eksperimen.

KEYWORDS: dynamic wireless charging; inductive wireless charging; ferrite core; electric vehicle $(E V)$ 


\section{INTRODUCTION}

An Electric Vehicle (EV) is an automobile vehicle that operates entirely on electricity without the emission of gases typical of conventional cars. The working principle is straightforward and plays a role in preventing environmental degradation. EVs can be associated with the use of an electric motor for propulsion and powering by electricity, either by plug-in, battery, or solar panel sources. This vehicle is not a new concept but was instead developed in the mid-18th century. However, during the 20th century, EVs became obsolete because of their limited driving range and high price compared to gasoline-powered vehicles. It is expected that by 2050 , the number of vehicles on the road is expected to reach up to 2.5 billion [1].

Regarding the future transport significance, EVs are considered the likely replacement for internal combustion engine-driven vehicles. EVs can reduce carbon discharges by reducing $\mathrm{CO}_{2}$ emissions, air pollution, and reliance on imported fuel [2]. The government of Malaysia also encourages electric cars by providing a total EV tax exemption [3]. Due to this, EV technology has captured the world's attention. Many researchers have realized the significance of EV; thus, intense studies have been reported on this technology.

EVs have rechargeable batteries onboard, as shown in Fig. 1. The power source no longer uses oil or gas and eliminates emissions since EVs are $100 \%$ electrical transportation. Instead, their source of power comes from a battery pack. This battery pack is charged using a wireless power transfer method. The primary transmitter coil acts as a transmitter to transmit the power from a primary to a secondary. The vehicle's pick-up coil acts as the receiver, also known as the secondary, in order to charge the battery pack. Referring to Fig. 1 , the fully charged battery pack acts as the energy source to drive the traction motor inside the vehicle. As with gas emission transports, the battery pack of an EV needs to be recharged first.

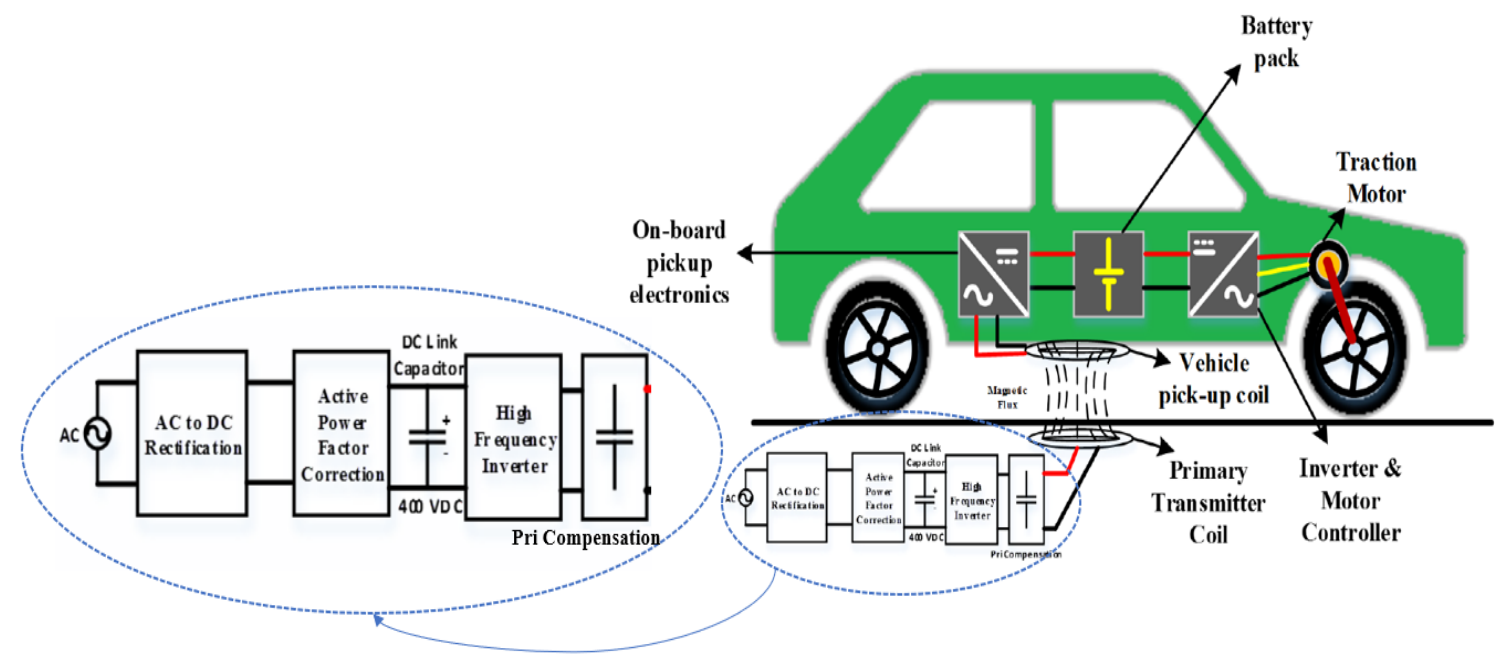

Fig. 1: Electric Vehicle (EV) System Model [4].

Battery recharging for EV can be done in three different ways, as stated by [5]:

1) static charging;

2) quasi-dynamic charging;

3) dynamic charging. 
Contactless charging or wireless charging is a new technology for EV power transfer. Charging is done using a wireless power transmitter and receiver to supply continuous power to the EV. A few years back, EVs only used Static Wireless Charging (SWC), where the vehicle needed to stay in the charging area throughout the recharge time. The problem or limitation in this technology is that the vehicle can only be charged when parked or in stationary modes such as parked in car parks and garages, or waiting at traffic lights [6]. The significant issues in public acceptance of EV correlate to its high battery cost and limited driving range.

The lithium-ion battery is widely used as the primary power source for the EV's drivetrain due to its high specific energy (100-265 W/kg) and specific power density (250$340 \mathrm{~W} / \mathrm{kg}$ ) compared to other battery technologies. Despite its superior characteristics, such a battery still adds considerable weight and size to the vehicle. For example, Nissan Leaf's $24 \mathrm{kWh}$ battery pack weighs around $200 \mathrm{~kg}$. In addition to high weight and size, the estimated price for an EV is about double that of its gasoline counterparts, with nearly half of the cost going toward the battery alone [7]. The limited driving range is an even more significant obstacle to the market penetration than the vehicles' higher cost. For example, gasoline vehicles can go over $500 \mathrm{~km}$ before refueling, which takes about 2-3 minutes at a filling station located every few kilometers.

On the other hand, most EVs can only go about 100-200 km before requiring another round of recharging that can last from about 30 minutes to more than 12 hours [8]. Besides this, charging stations are not as readily available as fuel stations. These limitations of static charging EVs has awakened researcher interest in a new dynamic charging method. The power transmission coil concept is used by the WPT method to transfer electric power from the primary grid source to energize the EV [9]. For a dynamic WPT, the vehicle needs to be charged while moving. Thus, the significant problem of high-power loss is encountered. This high-power loss is due to significant air gaps and misalignment between the primary and secondary pads [10]. When the loss is significant, the efficiency of power transfer is low.

Much research has been done to mitigate the mentioned problem [11,12]. However, none have come out with the optimal solutions and high-power efficiency. The other problem related to power loss is also due to low magnetic flux density. As the air-gap increases or misalignment occurs between the primary and secondary pad, the magnetic flux density is also reduced. Magnetic flux density is proportionally related to the induced current, thus directly affecting the power produced. As a result, low power transfer is due to having low magnetic flux density in primary and secondary coils. Some researchers have suggested including a ferrite core inside the primary and secondary coils. However, the design of the ferrite core is still an open issue. Adding an unsuitable ferrite core design can lead to unwanted additional weight and an increase in the manufacturing cost. That is why, even today, these problems are still in open research.

The research in this paper builds upon the improvements of previous research on novel ferrite cores [13] in wireless charging for EV applications. In this paper, Inductive Wireless Power Transfer (IWPT) uses coils embedded in the roadway and the vehicles. The IPT system consists of a pair of loosely coupled coils as transmitter and receiver. When the current flows through the coils, the magnetic field will be generated and thus will provide a wireless power transfer [14]. Figure 2 shows the Inductive Wireless Power Transfer System. 


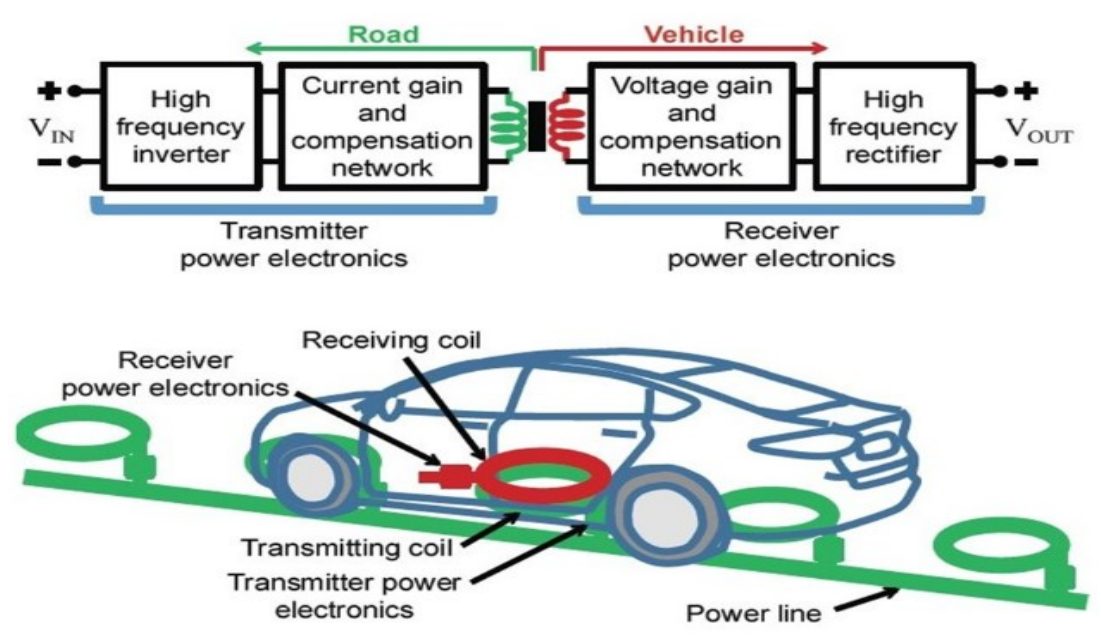

Fig. 2: Inductive WPT system [15].

\section{METHODOLOGY}

This section will discuss the proposed methodology used in designing the wireless charging system. Figure 3 shows the steps involved: calculation of coil parameters, identification of core shape, experimentation, and evaluation of results obtained. Next, subsection 2.1 will discuss the process of design and simulation using JMAG Designer 14.0. Finally, subsection 2.2 is the preparation of experimental work. In this study, the U and I ferrite core characteristics were investigated using two techniques. The first technique used a simulation on JMAG Designer 14.0. The simulation work was crucial for obtaining magnetic flux density for each pair of ferrite cores. Six designs of ferrite core, as shown in Table 1 , were run in this simulation. In addition, air-gaps of $1 \mathrm{~cm}$ and $2 \mathrm{~cm}$ with no misalignment was tested on all pairs of the ferrite cores.

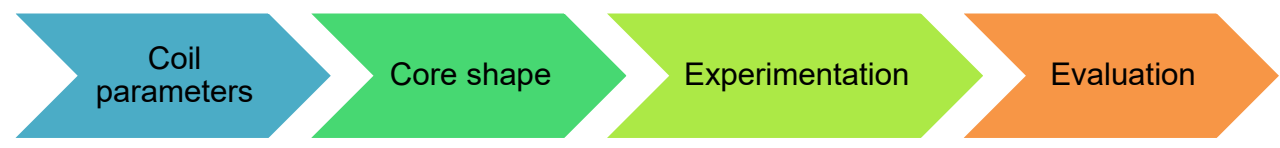

Fig. 3: Steps for designing inductive charging coupler.

The second technique used in this paper conducted an experiment to obtain the results from the prototype. The experiment was conducted in the university laboratory. From the simulation and experiment analyses, the power efficiency results were compared to each other in order to select the combination of ferrite cores that gave greatest power transfer. The calculation of parameters was first calculated, as discussed in [16]. In this paper, the power required for the EV was ratioed down to $16.7 \mathrm{~W}$. In an actual application, $36 \mathrm{~kW}$ of power would be required. Table 2 shows the parameters used in this study. Table 2 lists the primary and secondary voltages, primary and secondary currents, load resistor, primary and secondary inductances, mutual inductance, and primary and secondary capacitors.

Figure 4 shows the flowcharts for the a) first and b) second technique, for simulation in JMAG Designer 14.0 and experimental work. By using the JMAG software, the magnetic flux of each ferrite pair was measured. For the U ferrite core's shape, there are three possible ways to wind the copper coil around the $U$ core. Therefore, this study focused on winding the copper coil around the $U$ core. Table 3 shows the winding method around the $U$ shape. The three different winding methods were examined only for the $U$ shape, while the coil was simply wound at the central limb for the I core. 
Next, the final part of this study experimented on six pairs of ferrite cores. The experiment varied the air-gap from $1 \mathrm{~cm}$ with $0 \mathrm{~cm}$ to $5 \mathrm{~cm}$ misalignment. Section 3 will show the performance evaluation of each pair.

Table 1: Six pair of ferrite core

Secondary side
Primary side
Pair 1: Primary U ferrite core and secondary coil
$\begin{aligned} & \text { Pecondary side } \\ & \text { Primary side }\end{aligned}$
$\begin{aligned} & \text { Pair 4: Primary I ferrite core and secondary coil } \\ & \text { Pair 2: Primary coil and secondary U ferrite core }\end{aligned}$
$\begin{aligned} & \text { Pecondary side } \\ & \text { Primary side }\end{aligned}$
Pair 3: Primary and secondary U ferrite core
Primary side

Table 2: Calculated parameters for WPT system

\begin{tabular}{cc}
\hline Parameters & Values \\
\hline $\boldsymbol{V}_{\boldsymbol{p}, \boldsymbol{r m s}}$ & $12 \mathrm{~V}$ \\
$\boldsymbol{V}_{\boldsymbol{s}, \boldsymbol{r m s}}$ & $5 \mathrm{~V}$ \\
$\boldsymbol{I}_{\boldsymbol{P}, \boldsymbol{r m s}}$ & $1.39 \mathrm{~A}$ \\
$\boldsymbol{I}_{\boldsymbol{s}, \boldsymbol{r m s}}$ & $3.33 \mathrm{~A}$ \\
$\boldsymbol{R}_{\boldsymbol{L}}$ & $1.5 \Omega$ \\
$\boldsymbol{L}_{\boldsymbol{P}}$ & $330.72 \mu \mathrm{H}$ \\
$\boldsymbol{L}_{\boldsymbol{s}}$ & $36.65 \mu \mathrm{H}$ \\
$\mathbf{M}$ & $22.0 \mu \mathrm{H}$ \\
$\boldsymbol{C}_{\boldsymbol{p}}$ & $113.3 \mathrm{nF}$ \\
$\boldsymbol{C}_{\boldsymbol{s}}$ & $1022.4 \mathrm{nF}$ \\
\hline
\end{tabular}




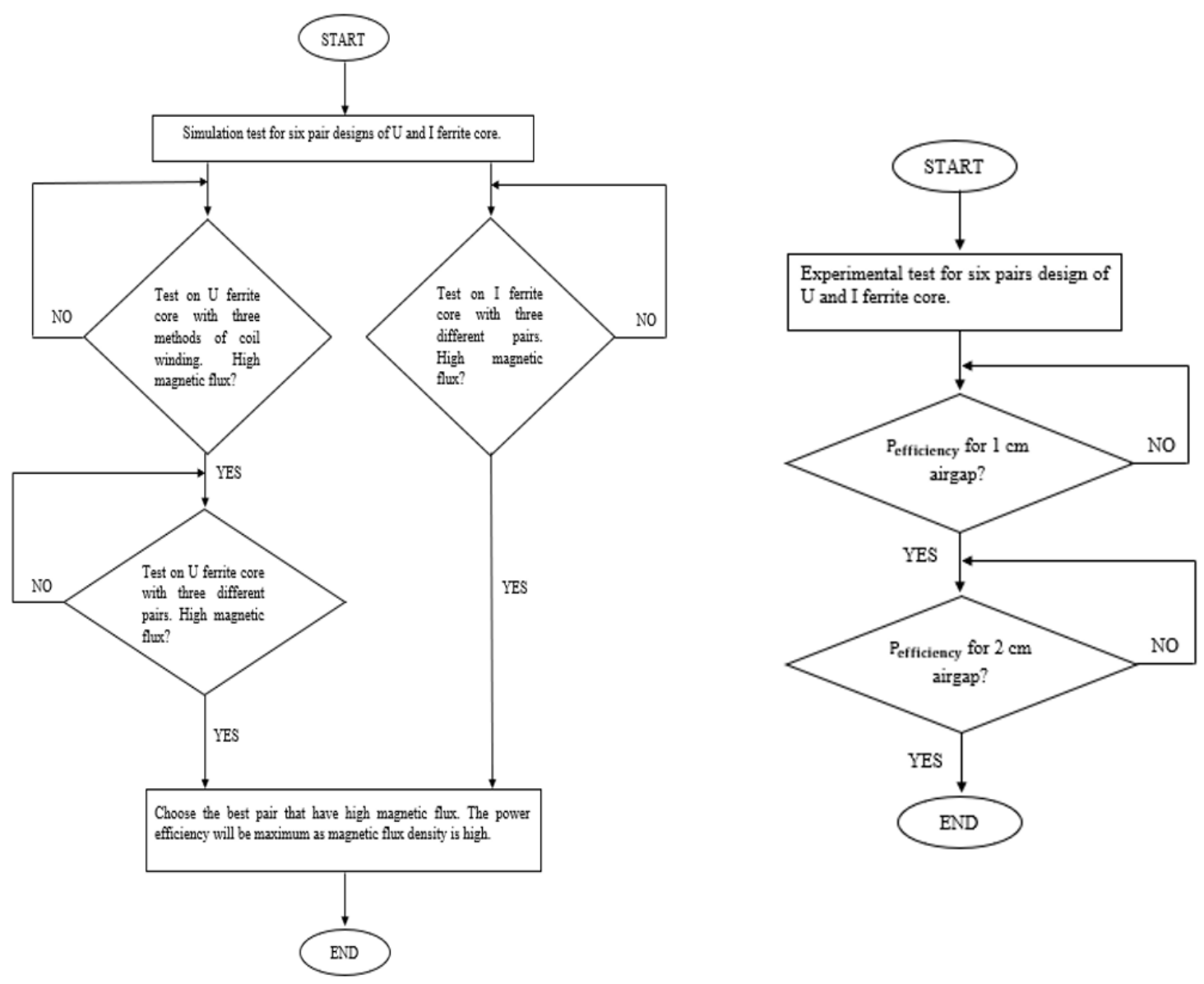

Fig. 4: Flowchart of a) first technique b) second technique.

Table 3: Winding method for U shape

\begin{tabular}{l} 
No. $\quad$ Winding Method for U shape \\
\hline $1 \quad \begin{array}{l}\text { Central winding: The copper coil is winding } \\
\text { at the center of the U ferrite core. }\end{array}$ \\
2 Edge separate winding: The copper coil is \\
winding separately at two edges of the U \\
ferrite core.
\end{tabular}

\subsection{Simulation Using JMAG 14.0}

Table 4 displays the geometry editor for six ferrite core pairs created in JMAG 14.0 before running the simulation. 
The blue, red, and yellow colors in all figures are indicated as follows:

1. The blue color indicates ferrite core at primary side

2. Red color is the secondary side.

3. Yellow color indicates the winding of the copper coil.

Table 4: Simulation using JMAG Designer 14.0

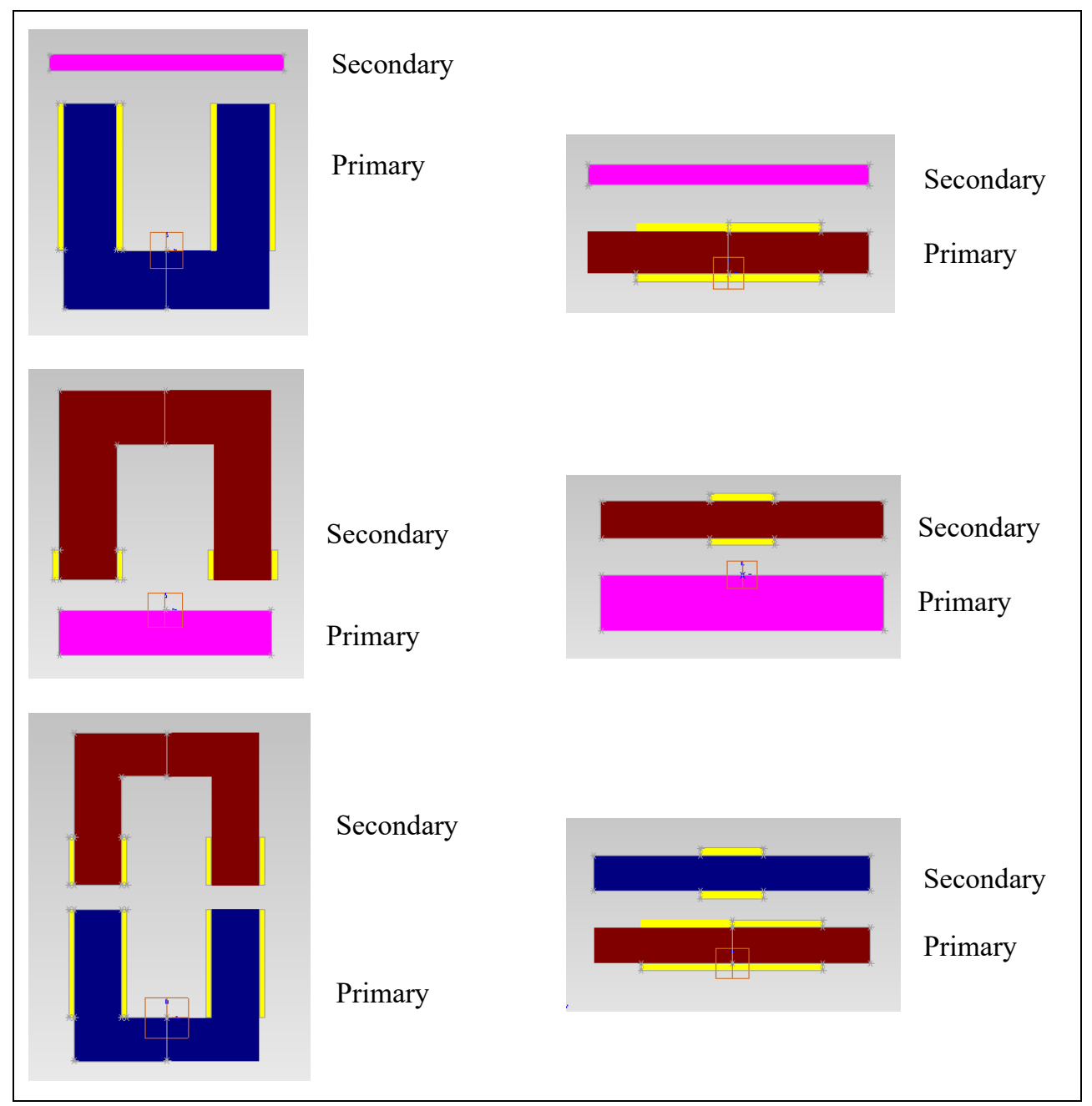

\subsection{Experimental Setup}

The wireless power transfer circuit was constructed before conducting the experiment. Transmitter and receiver circuits were constructed using fritzing software. Figure 5 shows the construction of the transmitter (primary circuit), while Fig. 6 shows the receiver (secondary circuit).

\section{RESULTS}

This section contains two subsections to evaluate the obtained results. Subsection 3.1 will discuss the simulation results from running the design in JMAG Designer. In this subsection, two main parts to run the simulation in JMAG designer software will be discussed. The first part is crucial for the $U$ ferrite core to identify the most suitable method to wind the copper coil around the U ferrite core. This part is crucial because the U shape's 
geometric design creates many possibilities to wind the coil, unlike the I ferrite core. Therefore, three different methods were investigated to choose the best winding to create high magnetic flux. After a few tests, the best coil winding was identified: method 2, edge separate winding. Then, the six pairs of ferrite cores listed in Table 1 were simulated using this software. Finally, among the six pairs, one pair was selected as the best ferrite core pair for the WPT system. The selection mainly focused on the highest magnetic flux produced.

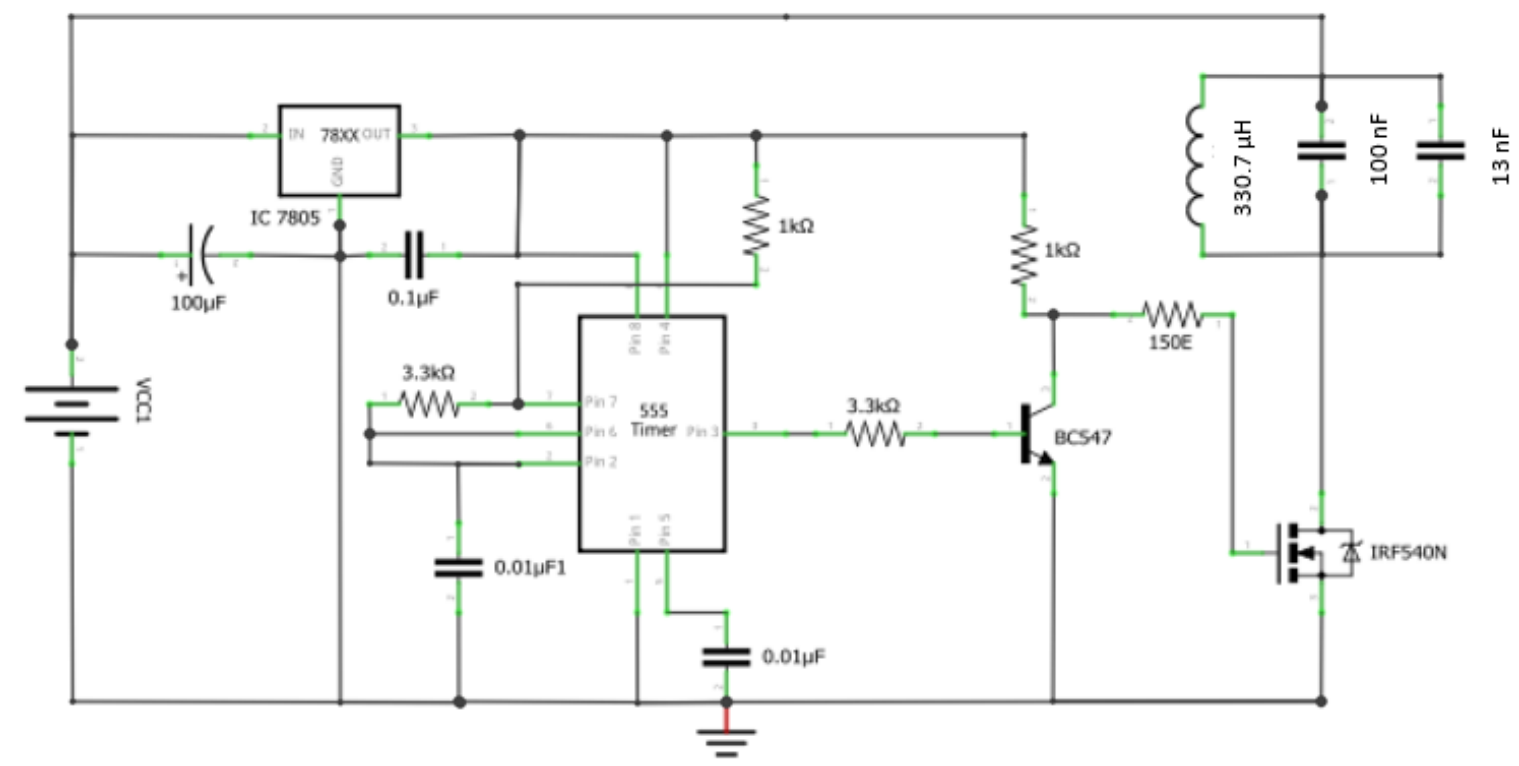

Fig. 5: Transmitter or Primary Circuit.

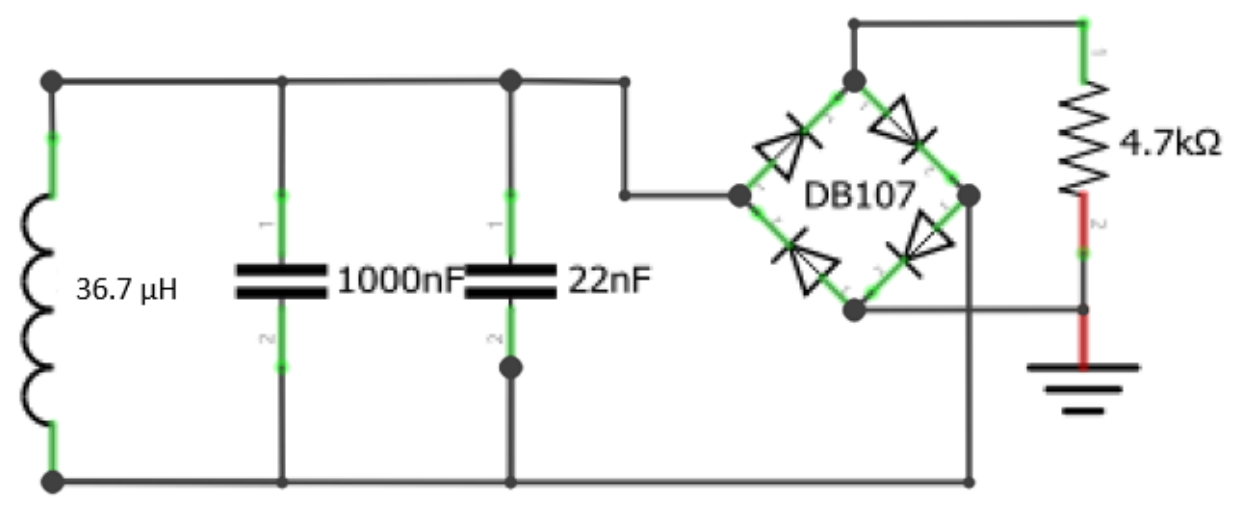

Fig. 6: Receiver or Secondary Circuit.

\subsection{Simulation Using JMAG 14.0 Software}

Table 5 shows the magnetic flux density of six pairs of the ferrite cores. The simulation of the JMAG designer provided a color region to indicate the strongest or weakest areas around the coil, U, and I ferrite cores. For all results of the three pairs, the color scale regions are shown together, with the strongest point identified. Note that all the simulation pairs are at a $1 \mathrm{~cm}$ air-gap. 
Table 5: Magnetic flux density for six pairs of ferrite core

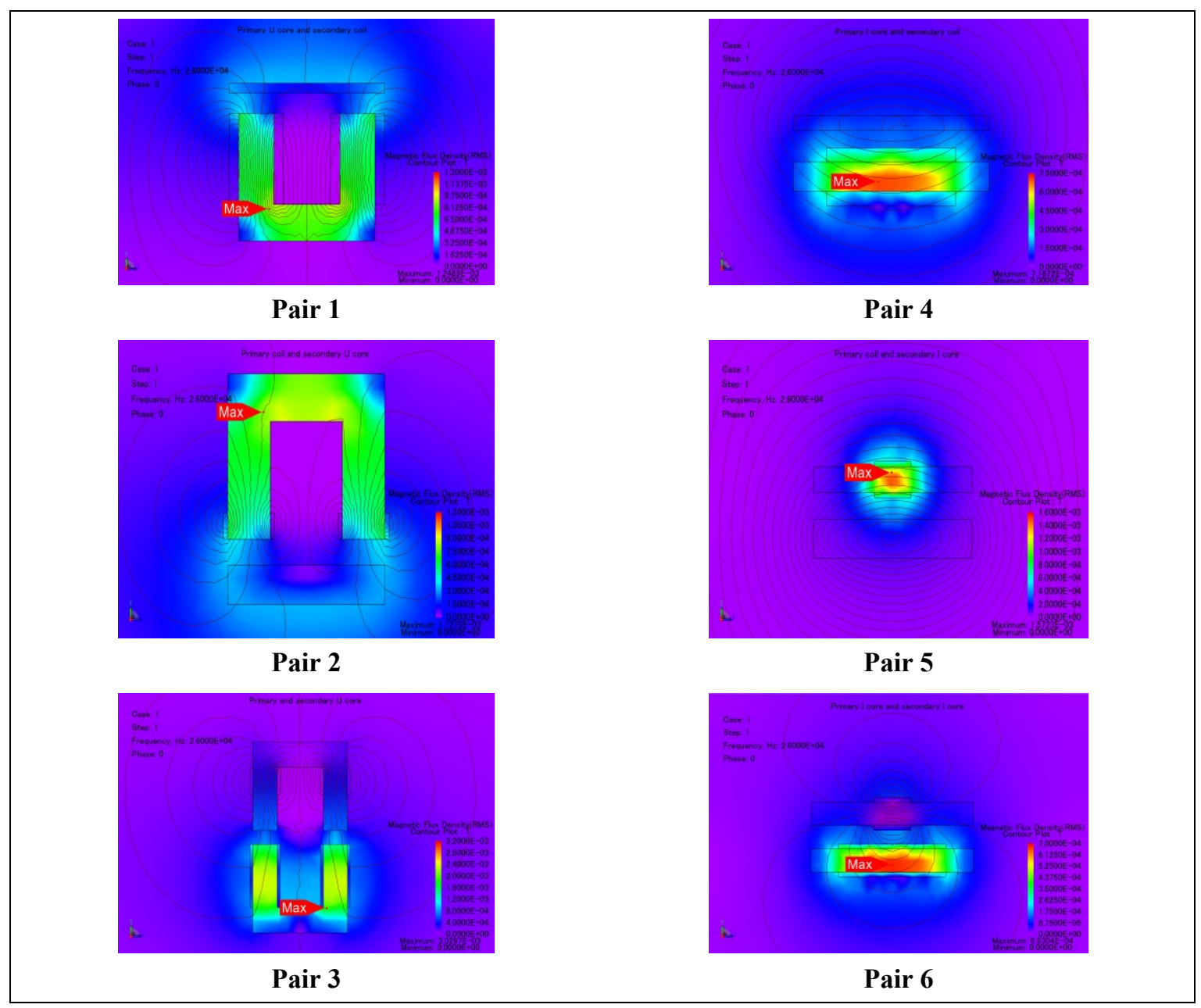

All six proposed design pairs in this study have been simulated using JMAG Designer. The magnetic flux obtained for each pair is shown in Fig. 7. Overall, as the air-gap between primary and transmitter increased, lower magnetic flux was produced. This result is because more flux leakages are created as the distance between the two sides increases. Thus, the best pair with high magnetic flux is pair 3 , in which the $U$ ferrite core is located at the primary and secondary sides.

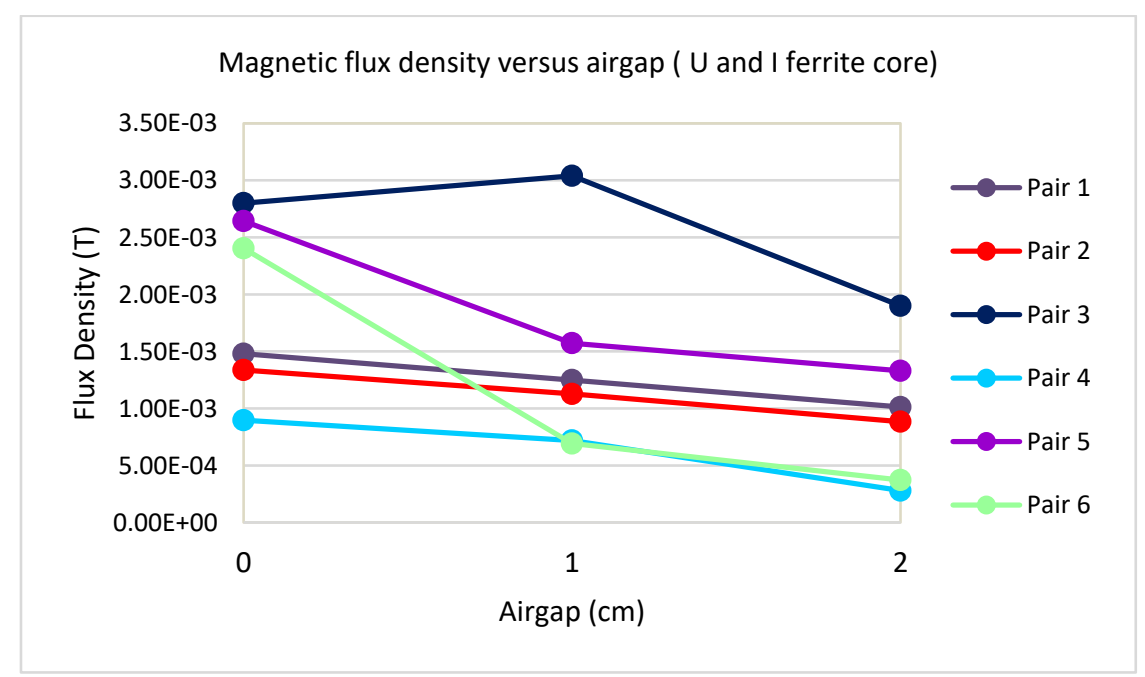

Fig. 7: Magnetic flux density for six coil pair designs. 
The electric power efficiency was calculated and plotted for all six pair designs, as shown in Fig. 8. In this simulation result, a pair of $U$ ferrite cores at both the primary and secondary sides, known as pair 3, offered the best power efficiency among the other pairs, followed by pair 5 . At $0 \mathrm{~cm}$ air-gap, the power of efficiency of this pair was $90.3 \%$. By increasing the air-gap to $1 \mathrm{~cm}$, the power efficiency was about $94.69 \%$. However, if the air-gap was increased to $2 \mathrm{~cm}$, the power efficiency dropped to a level similar to the other pairs.

Meanwhile, pair 6 showed good performance when there was no air-gap. Surprisingly, it showed rapid drops when the air-gap increased to $1 \mathrm{~cm}$ and slowly fell at the $2 \mathrm{~cm}$ airgap. The performance of power efficiency pair 1 and pair 2 was almost the same throughout the air-gap. The lowest efficiency pair was the primary I ferrite core and secondary coil, known as pair 4 . The power efficiency was consistently below $60 \%$ in every air-gap. Comparing the graph of magnetic flux versus air-gap from the Fig. 7 and power efficiency versus air-gap in Fig. 8, shows that the relationship between magnetic flux and power produced is directly proportional. Therefore, a pair design must have a high magnetic flux density to serve maximum power transfer.

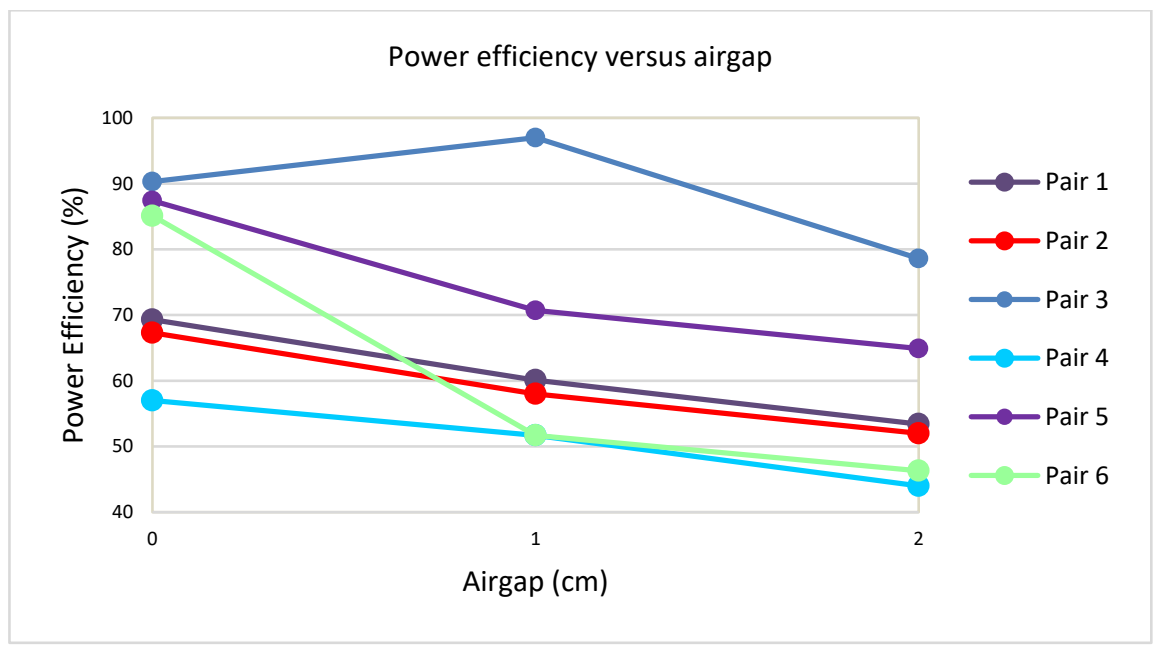

Fig. 8: Power efficiency with varies air-gap for six coil pair.

\subsection{Experimental Results}

This section evaluated the collected results for all pairs of $U$ and I ferrite cores. The main case was the performance of all tested pairs while varying the misalignment at a $1 \mathrm{~cm}$ air-gap. In this experiment, a mini prototype was built to test the proposed designs in this study. Even though the standard air-gap for a real EV is $8 \mathrm{~cm}$ until $10 \mathrm{~cm}$, an air-gap of 1 $\mathrm{cm}$ was used in this experiment as a starting development for the EV charging system. Figure 9 shows the percentage of power transfer versus misalignment between the primary and secondary sides. The highest power transfer delivered was from pair 3 (the $\mathrm{U}$ ferrite core at the primary and secondary side) with $94.69 \%$, followed by pair 5 at $89.7 \%$. As shown in Table 1, these two pairs use ferrite cores at both sides, primary and secondary. Therefore, it shows that the existence of a ferrite core in the system improves the power transfer. Then, pairs 1 and 6 have the same amount of power transfer at $15 \mathrm{~mm}$ misalignment with $51 \%$ of power transfer. While pairs 2 and 4 have an equal amount of power delivered, which is $49.7 \%$ at $10 \mathrm{~mm}$ misalignment. Overall, the power transfer delivered showed a constant decrease from $0 \mathrm{~mm}$ to $50 \mathrm{~mm}$ misalignment. As the distance between primary and secondary increased, more flux leakage occurred and reduced the power obtained at the primary side. 


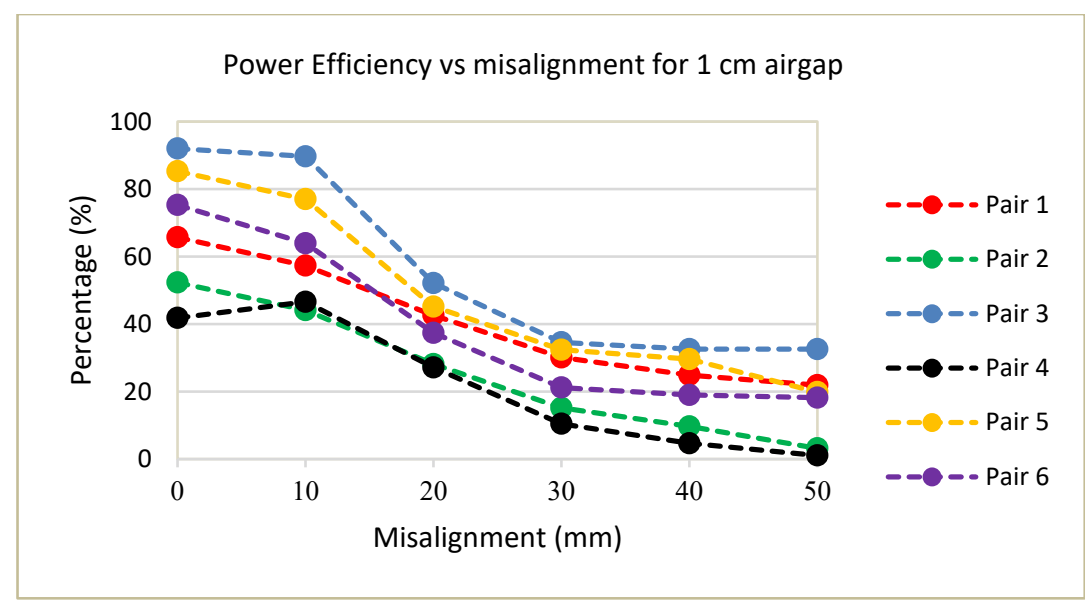

Fig. 9: Power efficiency at $1 \mathrm{~cm}$ air-gap.

Figure 10 shows the final prototype of this project. The experiment was conducted in the laboratory with the equipment provided. A $1 \mathrm{~V}$ DC voltage was supplied to the primary circuit and transferred to the secondary circuit. The figure below labels the power supply and oscilloscope to calculate the power obtained, and the primary and secondary sides of the system. As discussed previously, the best pair of ferrite cores is pair 3. As shown in Fig. 10 , the proposed design of pair 3 is a $\mathrm{U}$ ferrite core at both the primary and secondary sides.

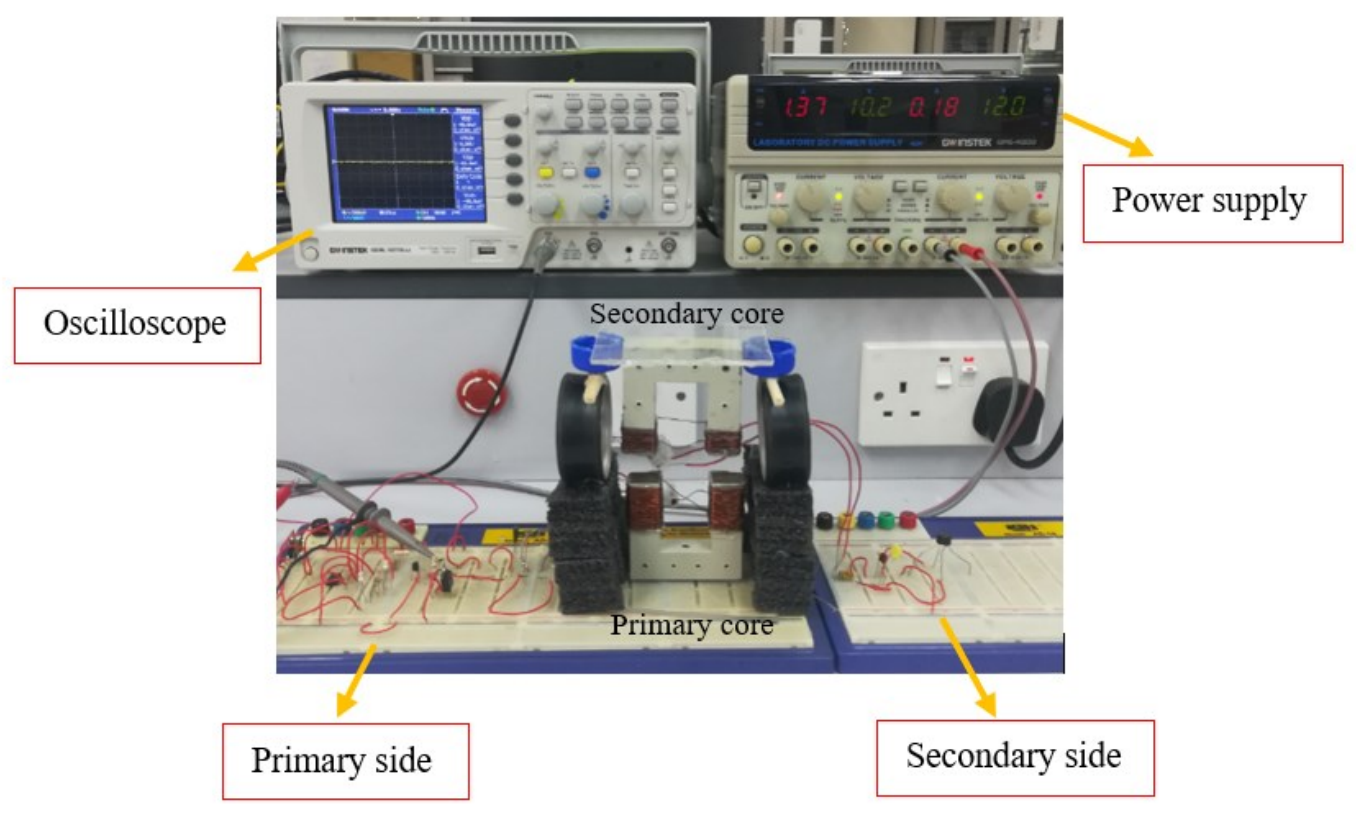

Fig. 10: Pair 3, best pair of U ferrite core.

To conclude, the best pair design was pair 3, which is the primary and secondary U ferrite core. The $U$ ferrite core can reduce the leakage of magnetic flux and experience high magnetic flux density, as shown in Fig. 7. The magnetic flux density for this pair is the highest among all the pairs, which is $3.00 \mathrm{E}-03 \mathrm{~T}$. Since this pair had a high magnetic flux density, the power transfer efficiency was also high. Figure 9 shows that pair 3 with high magnetic flux density also had high power transfer, which was $94.69 \%$. Therefore, the U shaped ferrite core is excellent for a wireless charging system because of its better magnetic flux distribution and reduced flux leakage. The design of the $U$ ferrite core can reduce the flux leakage by feeding back the magnetic fluxes into the core and to the secondary side 
[17]. Therefore, it is proven that the pair design of $U$ ferrite cores at the primary and secondary sides was the best design that gave high magnetic flux and led to the maximum power efficiency of WPT, as mentioned by Pathipati et al. [13]. The extension of this research is that there is a pair where the ferrite core is not at both sides simultaneously. Previous research by Pathipati et al. [13], who also investigated the ferrite core, proposed that all the designs have a ferrite core in both the primary and secondary sides. Instead of using a ferrite core at both sides, this thesis investigated a different pair if one of the sides was a copper coil and the other was a ferrite core. Running the JMAG Designer and experiment test showed the lower power efficiency pair was pair 4, the primary I ferrite core and the secondary coil. This result was due to high magnetic flux and power transfer leakage occurring without the ferrite core at the secondary side.

Here, table 6 lists the comparison of power transfer obtained from these two techniques. The first technique was to obtain the magnetic flux density produced between the primary and secondary sides by running JMAG designer 14.0. The second technique was by experimenting with obtaining power transfer for each pair of the ferrite cores. In both techniques, pair 3 showed a high performance compared to other pairs. The different power efficiency from the experiment and JMAG Designer software was about $4.99 \%$. This slight difference in power efficiency was due to equipment limitations, inductance values, and other factors that led to the error.

Table 6: Power efficiency of pair 3 in simulation and experiment test

\begin{tabular}{ccc}
\hline Method & JMAG Designer & Experiment \\
\hline $\mathrm{P}_{\text {efficiency }}(\%)$ & 94.69 & 89.7 \\
\hline
\end{tabular}

Static wireless charging allows the recharging process to take place once the vehicles is located above the charging plate and must be static. Dynamic wireless charging is better suited to recharging the battery pack while in motion. However, the biggest elements that must be tolerated with the dynamic wireless charging system is air-gap and misalignment. Even though many studies show the effectiveness of a wireless pad design using ferrite cores, they rarely proposed an effective method to solve the problems by varying the geometric shape of the ferrites. The misalignment between the primary and secondary coils has an impact on the dynamic charging system performance. Among them are the power fluctuation from the transmitter to the receiver coils if the EV is moving. This power fluctuation also means that the coupling coefficient changed with motion. Meanwhile, for static charging, even with misalignment, the power fluctuation did not occur as the EV stayed in one place during the charging process. Therefore, the coupling coefficient stayed constant until the EV was fully charged.

\section{CONCLUSION}

In this paper, a prototype of a wireless charging system for EVs was developed. Before conducting the experiment, a literature review and simulation work were first carried out. Then, six pairs of ferrite cores were proposed in this study to select which pair showed better delivered power. The observation showed that the reduction of power transfer was caused by increasing the distance between the primary and secondary sides. The performance of the system in this study was that it can produce $1.8 \mathrm{~W}$ of delivered power. Although the prototype's performance was prolonged to charge the real EV charging system, this paper has proven that power can be transferred from one medium to another wirelessly using the inductive coupling principle. 


\section{ACKNOWLEDGEMENT}

This work was partially supported by the Ministry of Higher Education Malaysia under IIUM-UMP-UiTM Sustainable Research Collaboration Grant 2020 (SRCG) number SRCG20-049-0049.

\section{REFERENCES}

[1] Kumar PP, Abd Halim A. (2018) Electric-based national car proposal being developed. The Malaysian Reserve, https://themalaysianreserve.com/2018/07/26/electric-based-national-carproposal-being-developed/

[2] Tian Y, Li D, Tian J, Xia B. (2016) A Comparative Study of State-of-Charge Estimation Algorithms for Lithium-Ion Batteries in Wireless Charging Electric Vehicles. IEEE PELS Workshop on Emerging Technologies: Wireless Power, WoW 2016, no. 2016, pp. 186-190. doi: 10.1109/WoW.2016.7772089

[3] Zaini SA, Yusoff SH, Abdullah AA, Khan S, Abd Rahman F, Nanda NN. (2020) Investigation of Magnetic Properties for Different Coil Sizes of Dynamic Wireless Charging Pads for Electric Vehicle (EV). IIUM Engineering Journal, 21(1): 23-32.

doi: https://doi.org/10.31436/iiumej.v21i1.1108

[4] Pathipati V. K., Azeez N. A., Aditya K., Williamson S. S., Dohmeier and Botting N. C. (2016) Performance Analysis of a High-efficiency Multi-winding Wireless EV Charging System Using U-U and U-I Core Geometries, 2016 IEEE Transportation Electrification Conference and Expo (ITEC): pp. 1-8. doi: 10.1109/ITEC.2016.7520243.

[5] Ahmad A, Alam MS, Chabaan R. (2017) A Comprehensive Review of Wireless Charging Technologies for Electric Vehicles. IEEE Transactions on Transportation Electrification, 4(1): 38-63. doi: 10.1109/TTE.2017.2771619.

[6] Panchal C, Stegen S, Lu J. (2018) Review of Static and Dynamic Wireless Electric Vehicle Charging System. International Journal Engineering Science and Technology, 21(5): 922937. doi: 10.1016/j.jestch.2018.06.015

[7] Aditya K, Williamson S. (2019) Design Guidelines to Avoid Bifurcation in a Series-Series Compensated Inductive Power Transfer System. IEEE Transactions on Industrial Electronics, 66(5): 3973-3982. doi: 10.1109/TIE.2018.2851953

[8] How long does it takes to charge an electric car? (2016) Pod Point, 2016. https://podpoint.com/guides/driver/how-long-to-charge-an-electric-car

[9] Nanda NN, Yusoff SH, Toha SF, Hasbullah NF, Roszaidie NAS. (2020) A Brief Review: Basic Coil Designs for Inductive Power Transfer. Indonesian Journal of Electrical Engineering and Computer Science, 20(3):1703-1716. doi: 10.11591/ijeecs.v20.i3.pp1703-1716.

[10] National Academy of Engineering (2018) Frontiers of Engineering: Reports on Leading-Edge Engineering from the 2017 Symposium, The National Academies Press, , Washington, DC. 37-46. https://doi.org/10.17226/24906.

[11] Varikkottil S, Febin Daya JL. (2019) Estimation of Optimal Operating Frequency for Wireless EV Charging System under Misalignment. Electronics (Switzerland), 8(3) :342. https://doi.org/10.3390/electronics8030342.

[12] Kalwar KA. (2017) A Design Method for Developing a High Misalignment Tolerant Wireless Charging System for Electric Vehicles. Journal of the International Measurement Confederation (Measurement). doi: https://doi.org/10.1016/j.measurement. 2017.12.013

[13] Pathipati VK, Azeez NA, Aditya K, Williamson SS, Dohmeier N, Botting C. (2016) Performance Analysis of a High-efficiency Multi-winding Wireless EV Charging System Using U-U and U-I Core Geometries. IEEE Transportation Electrification Conference and Expo, ITEC 2016. doi: 10.1109/ITEC.2016.7520243. 
[14] Wan Noor Nadira Wan Fauzi, Mohamad Syafiq Mazli, Sheroz Khan, Khairil Azhar Adnan, Ezzidin Hassan Aboadla, Majdee Tohtayong, Mashkuri Yaacob (2018) Beaming of Inductive Field with an Asymmetric Four-Coil Resonator for Wireless Power Transfer, 2018 7th International Conference on Computer and Communication Engineering (ICCCE). 301-305. https://doi.org/10.1109/ICCCE.2018.8539312.

[15] Patrick P. Mercier, Anantha P. Chandrakasan (2015) Ultra-Low-Power Short-Range Radios, Springer, Cham. 343-375. https://doi.org/10.1007/978-3-319-14714-7

[16] Aditya K, Sood VK, Williamson SS. (2017) Magnetic Characterization of Unsymmetrical Coil Pairs using Archimedean Spirals for Wider Misalignment Tolerance in IPT Systems. IEEE Transactions on Transportation Electrification, 3(2): 454-463. doi: 10.1109/TTE.2017.2673847.

[17] Panchal C., Lu J. and Stegen S. (2013) Investigation of magnetic flux distribution of EV wireless charging systems, 2013 Asia-Pacific Symposium on Electromagnetic Compatibility (APEMC). 1-4. doi: 10.1109/APEMC.2013.7360652. 